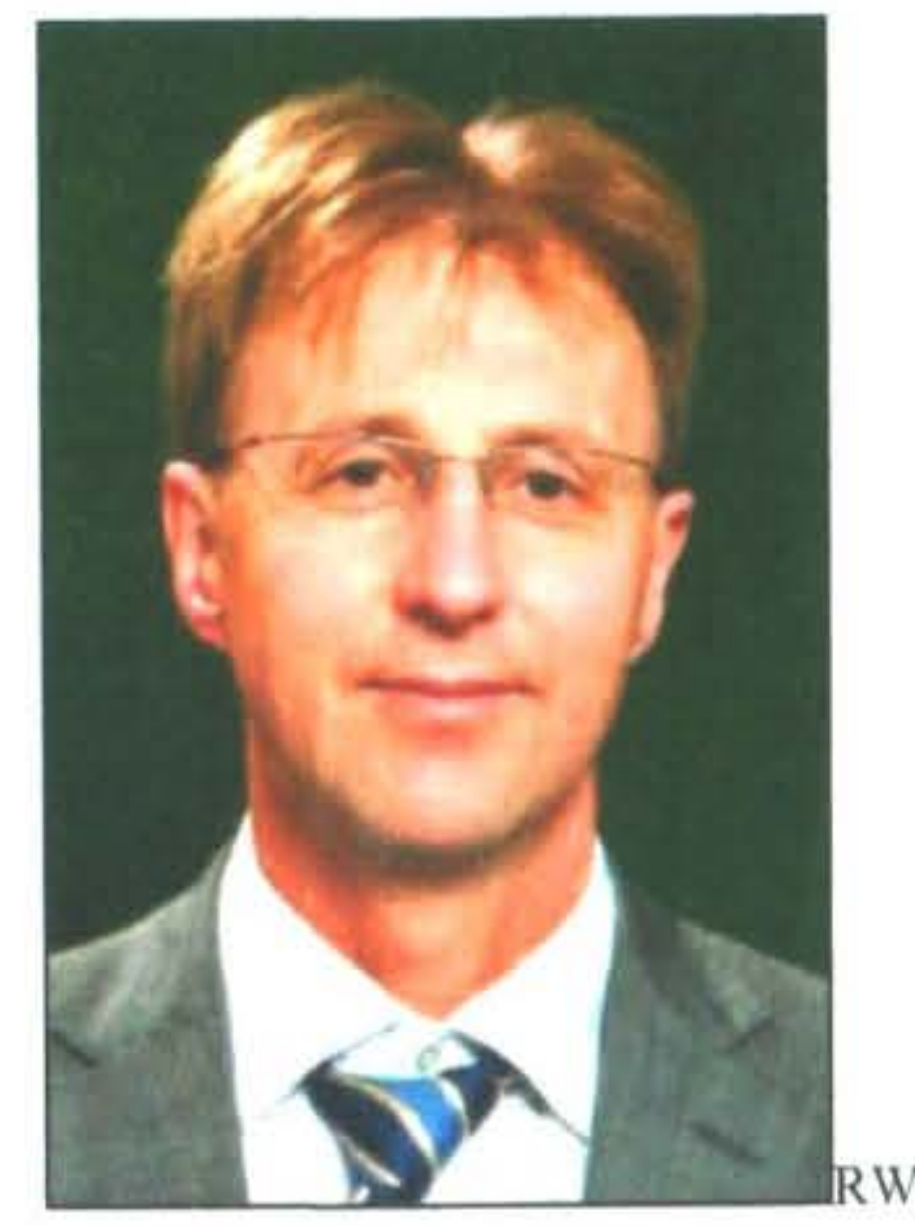

\section{THE SEASONAL LABOUR STRATEGY AND THE ROLE OF RECOGNISED SEASIONAL EMPLOYER (RSE) IN HELPING MAKE TRANSFORMATIVE CHANGES FOR EMPLOYERS AND INDUSTRY}

\section{Richard Whatman and Jerf Van Beek}

Department of Labour and Horticulture New Zealand

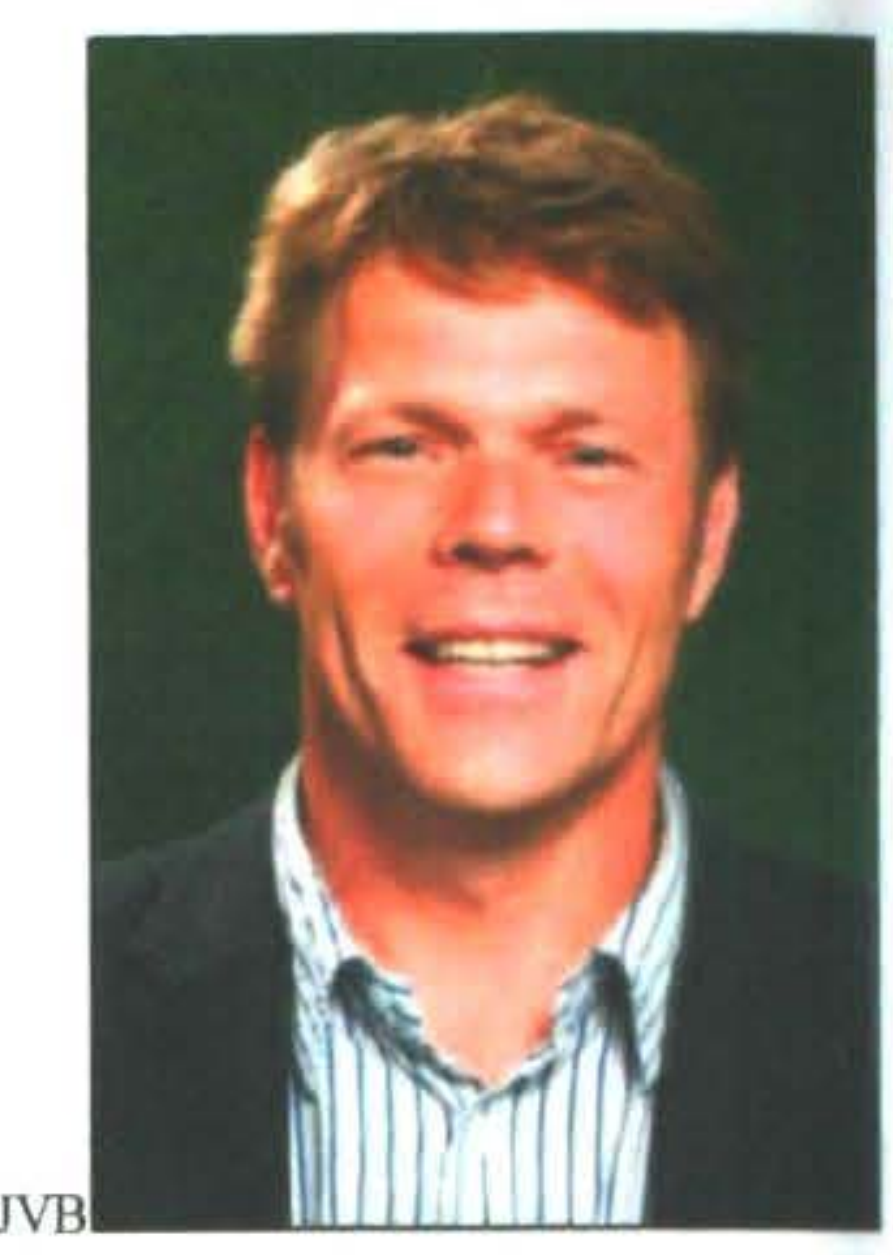

\title{
Abstract
}

The Recognised Seasonal Employer (RSE) scheme is the most prominent part of a broader labour market strategy for the horticulture and viticulture industries. The purpose of the Horticulture and Viticulture Seasonal Labour Strategy (the Strategy) is to transform the seasonal labour market, which this decade has been characterised by very low productivity, high turnover, and illegal work practices. This labour market failure has cost industry and the government hundreds of millions of dollars, though the full cost will never be known. The Strategy, working off the fulcrum of RSE, has been very successful in its early stages of implementation. There are many problems, but the trajectory of change is highly promising. This paper explores the conception, theoretical underpinnings and implementation of a unique experiment in labour market transformation, evidence of that transformation, where available, is referenced.

\section{Introduction}

The prospects for large growth in low-skilled temporary migration schemes around the world are good, principally because of aging populations in most developing countries. This could significantly assist developing countries, through remittances, skill development and new trading relationships. It could also assist developed countries, given severe labour shortages in many lowerskilled and labour intensive industries, through ensuring an on-going labour supply. There is a recent and growing literature from international organisations like the World Bank and OECD advocating greater use of migration as a development tool (Dayton-Johnson et al, 2006; World Bank, 2006).

The literature discusses the benefits and risks that have to be managed. Such as: the politically sensitive nature of low-skilled migration; or, the risks of "brain drain" for sending countries. The literature does not, however, fully discuss a fundamental issue for the sustainability of schemes - mitigation of the 'trap' of low cost and low productivity modes of production in receiving countries. It is not necessarily straightforward or easy to construct schemes that add value to receiving labour markets, given that those receiving labour markets may have considerable levels of dysfunction. The sensitive nature of low-skilled temporary migration means that the usual economic and regulatory incentives that could be deployed will not usually be sufficient to ensure timely adjustment and sustainability for the migration schemes.
Being able to identify the 'value-add' moments and construct a combination of interventions that will achieve them requires a different approach to normal "policy making" approaches. "Practice making" is argued to be a better approach; that is one which involves a range of stakeholders in the construction of shared objects and behaviours, then developing the policy needed to support them. This is an approach that is able to guide the development of complex adaptive systems, such as labour markets. The Horticulture and Viticulture Seasonal Labour Strategy and RSE in New Zealand and the Pacific are examples of this approach, which are having a profound effect on the productivity, viability and profitability of the Horticulture and Viticulture industries in New Zealand, and the beginnings of tremendous development outcomes in the Pacific. Rather than producing a low wage trap, RSE is underpinning a new approach amongst employers in Horticulture and Viticulture to the productive utilisation of labour; in turn this will produce better conditions and pay for the workforce. In turn this is providing confidence for expansion and development of new crops and approaches to production.

Low-skilled temporary migration can be used to improve labour productivity, wages and conditions in receiving countries as well as development outcomes in the sending countries. The development of the receiving country's labour market is arguably the most important issue in the development of low-skilled temporary migration schemes, that without the addition of new value in the receiving country's labour market, these schemes are likely to fail. 


\section{Solutions to Seasonal Labour Problems Required a New Approach}

Central Otago in New Zealand is blessed with an immense mountainous beauty. It is also a wonderful place for producing fruit such as cherries, plums, apricots and apples, and more recently wines of great character, particularly Pinot Noir. The very cold winters keep the pests at bay while the long hot and dry summers give ripened fruit intense flavours.

There are, however, a handful of unemployed in a region two-thirds the area of Northern Ireland. Over the past decade, New Zealand's horticulture and viticulture employers have gone from putting a box at the gate with "pickers wanted" to attract passing seasonal staff, to dire shortages while running a sophisticated employer cooperative of stonefruit, pipfruit and grape growers called Seasonal Solutions Central Otago (SSCO) to attract labour from on and off-shore. ${ }^{1}$ While SSCO was a successful innovation, and helped with the labour problems in the area, it was not sufficient in itself. In part because the problem was a national one, and in part because a secure, returning labour supply was essential for the sector and SSCO could not generate that.

In Central Otago, $70 \%$ of the staff used in horticulture and viticulture are temporary migrants, but most are from Europe and other developed countries who are in New Zealand on working holidays. For the employers, this relatively wealthy and recreationally focussed workforce is unreliable and not very productive.

Two summers ago, $45 \mathrm{Ni}$-Vanuatu came to New Zealand to work for SSCO, mainly picking fruit. Bringing the 45 workers in was an experimental pilot for SSCO, the New Zealand government and the World Bank, who helped fund it. The experiment two years ago worked well for all concerned. This coming season, SSCO is planning to bring in over 500 workers from Vanuatu to work in Central Otago and Marlborough, many of these are now returning workers from previous seasons. The $260 \mathrm{RSE}$ workers in Central Otago will be about 5 percent of the workforce needed to pick, pack and maintain the crops in Central Otago, but will produce about 20 percent of the output of the workforce as a whole. ${ }^{2}$

In 2006-7, SSCO worked with the local community in Otago and the World Bank to provide training outside of work hours. The local high school opened its doors. Two-stroke motor maintenance was taught, and the internet, Google and cyberspace opened up to the workers a world of new opportunities.

Alex wrote in an email to one of the people that he had met in the New Zealand government before he went home:

"This is the day I have been waiting for, to get into this computer and can talk to friends which we have met. This is a privilege in knowing how to use this computer. This is an achievement for me to learn the computer in a foreign country. I would like to thank the Seasonal Solutions and the government of New Zealand for realizing that we need more than money to take home, but skills in can prepare us for a better job in New Zealand and also a better Vanuatu. I hope our small commitment in contributing to this nation's economy will not go unnoticed. Our prayer is that the doors of opportunity will slowly open and our relationship will a binding relationship in which we will see more Ni-Vanuatu people benefiting from it. Thank you very much and the Lord bless you."

This year SSCO has chartered Air New Zealand 737s for transporting large groups to and from Central Otago and Marlborough. RSE has contributed to the number of flights to Vanuatu from New Zealand having doubled. The development spin-offs have begun to impact on tourism, and things like the provision of government services.

These developments in Otago and Vanuatu are part of a larger change that is occurring in New Zealand and the Pacific as part of RSE. RSE came into operation in April 2007 to facilitate the temporary entry of up to 5,000 Pacific workers to work in horticulture and viticulture to 'pick, pack, prune or maintain' crops, once all 'suitable' New Zealander labour supplies have been exhausted. ${ }^{3}$ The New Zealand and Pacific Islands' governments and the New Zealand horticulture and viticulture industries, working with the Council of Trade Unions, have developed a Scheme that provides sustainable development paths for both New Zealand and the Pacific Islands' nations.

\section{Problems with temporary labour in labour intensive industries}

Labour-intensive industries in developed countries, like horticulture and viticulture, can create serious labour market problems. The margins for horticulture and viticulture commodities are often slim, with intense pressure from retailers to keep costs down, while requiring exacting quality. ${ }^{4}$ The seasonal nature of employment makes these industries difficult to staff when there are peak demands, and the nature of the product and quality requirements means that just-in-time production is the only profitable form of production; there are often very narrow tolerances for harvesting or other tasks.

As a result, most countries in the developed world struggle with a "wicked"s combination of: the demands of growers to meet labour needs; low wages and poor working conditions; the use of illegal migrant labour; poor quality work; and low labour productivity. In the United Kingdom, these problems are synonymous with the Morecombe Bay cockle tragedy, when twenty-three unlawful migrant Chinese cockle-gathers died (BBC, 2005; New Scotsman, 2005; Wellings, 2004)

The difficult labour market economics in these commodity industries (and other labour-intensity industries) then often becomes difficult politics. Pressures in equal measure collide - to ensure sufficient labour to continue production at low cost, while meeting local community concerns with itinerant workers, and 
human rights/union concerns about those same workers. What generally follows is resort to the 'regulatory pendulum', in which regulation and enforcement are tough then weak, oscillating between these irreconcilable tensions (Sparrow, 2000). In the UK, the Morecombe Bay tragedy has lead to the enactment of the Gang Masters Licensing Act 2006. In the USA Congress, the President and the country seem unable to manage the contradictions of illegal migration from South of the border. Perhaps this is exemplified most starkly by controversy of building the border barrier with Mexico, where the barrier will cover about one third of the border and have many consequences beyond border control.

Equally inexorable are the demographic trends in most developed countries that mean that low-skilled temporary migration will become essential to maintaining their economies. For example, the European Union will loose 65 million workers in coming decades, and is currently in negotiation with Pacific Forum countries (and others) for temporary work schemes in tourism and aged care. ${ }^{6}$

\section{Developing countries find it hard to develop agricultural exports}

Developing countries trying to grow primary products for export, they face the barriers of: subsidised production in many developed countries; tariffs and non-tariff obstacles like phytosanitary [essentially free of disease] requirements; lack of transport and storage infrastructure; or the ability to provide traceability of products. While labour costs may be low, these countries are likely to have low labour productivity because of lack of training and technology to raise productivity.

\section{Adjustment for developing and developed countries is slow and costly, and not without risk}

For both developing and developed countries there will be adjustment over time, with capital, production and labour migrating to the location that is most economically productive for those commodities to be produced. This adjustment has been going on apace in horticulture and viticulture, with China now the world's largest apple producer, Chile regarded as a country with improving quality, and more plantings proceeding rapidly in countries in Africa and South America.

This adjustment is not costless. Producers in the developed world risk loss of livelihood. The globalisation of production can lead to greater carbon emissions, or loss of habitat or productive land in both developed and developing countries. There are also: food safety, 'fair trade', and other potential risks that can arise in the process of accumulating knowledge and the systems needed for sustainable production.

\section{"Policy coherence" of trade, labour migration and aid}

The OECD and World Bank have contributed considerably to the literature on the use of migration to achieve development objectives. The essence of the economic and policy argument for both is that carefully designed schemes can produce good outcomes for sending (developing) and receiving (developed) countries. In particular they note that temporary lowskilled migration can produce very significant development gains through remittances and their multiplier effects, skills development; and establishing trading networks. These assist with the stability of the sending countries, while meeting labour needs in the receiving countries.

The OECD notes, however, that there is a lack of "policy coherence", with aid, trade and migration policies often pulling in contradictory directions. For example, training provided through aid budgets to raise human capital can result in "brain drain", or trade barriers which can reduce the ability of developing countries to export agricultural products. To achieve 'policy coherence', they argue, the arrangement of influences need mutually reinforce each other, and meet the needs of sending and receiving countries.

\section{"Policy coherence" is not sufficient to achieve sustainability in temporary, low-skilled migration schemes}

A lacuna in the literature is to concentrate on the policy requirements to maximise the benefits to sending countries. Fundamentally, for a scheme to succeed in the long-term - to be 'sustainable' - new value has to be created in the work undertaken by migrants in the receiving country. To do that, a thorough understanding of the dynamics of the labour market into which the workers are going, and the receiving country's purpose in their going, is required. If the worker's purpose is simply to maintain the labour market status quo that existed before the scheme, there are likely to be weak incentives for productivity improvement. Without productivity improvement, the labour market for their work may not be sustainable.

Sending country workers will be prepared to accept relatively low wages and poor conditions, while receiving country employers will want to keep labour costs down. These incentives may prevent the transition of industries to higher value production, and in effect subsidise poor performance. This may lock investment into uncompetitive industries which in the longer-run will be a brake on the receiving country's development, and may lead to a more catastrophic collapse of an industry as other lower-cost countries out-compete it on price. Over time, sending and receiving countries may loose all value from the enterprise.

Policy making, as a process, often misses important elements needed to address "wicked problems", because it is dealing with a complex adaptive system that resists reductive analysis (Chapman, 2004). Fundamental to systems of this type is that they are unpredictable: the impacts of particular policy interventions cannot be 
predicted; and feedback and feedforward loops will produce outcomes that are unintended. Outcomes might be worse than prior to the inventions. It is, inevitably, policy making that produces "policy incoherence" in the first place.

\section{Adaptive "practice making" is more likely to succeed than "policy making"}

Responding to a "wicked problems"/complex adaptive system requires humility in the face of its complexity; experimentalism and most particularly a learning and adaptive approach to development. In the case of RSE, this has been reflected in what has become to be called "practice making", as compared with "policy making" (Whatman, 2005). The distinguishing features of "practice making" are: identifying what people do as opposed to what they say they do within the overall system (using qualitative research processes described in detail elsewhere - Whatman ibid; Hill, 2007); sketching the overall system using systems analysis techniques; identifying what possible intervention points are available; setting up experiments to test the utility of those change points and the means of affecting behavioural change in them; and, most importantly, identifying the potential new value creation points as objectives participants in the system as a whole can collectively pursue.

The sensitivity of low-skilled migration schemes requires more than just aligning economic incentives and regulation. The timetable for economic adjustment is likely to be incompatibly long compared with social expectations. Success requires an active approach to the receiving labour market; an accelerated evolutionary approach that is managed without being controlled.

\section{A brief description of "practice making" in RSE}

Industry organisations (Horticulture NZ, NZ Wine, Pipfruit NZ, Kiwifruit Growers Incorporated), the Council of Trade Unions and government (the Department of Labour, Ministries of Social Development and Agriculture and Forestry, and IRD were the agencies involved) identified that there were a wide range of changes needed to transform the industry. This was done through a partnership chaired by Horticulture New Zealand and the Department of Labour, which developed the Strategy for change focused on sustainable seasonal labour (Horticulture $\mathrm{NZ}$ et al, 2005). There were four group works established, and then a fifth was added in 2006. The work groups were for: increasing retention and accessing of New Zealand workers; accessing global labour (with return migration being a significant new area of action, but also 'casual' labour such as Working Holiday Scheme visitors); accurate labour supply and demand information; skills training and productivity improvement, and the fifth being the development of a sound and professional labour contracting industry.
Innovative "practice making" research preceded the development of the Strategy, it identified the impact that seasonal labour has on the value of the crop and suggested areas of development for the industry. Common personnel from the Department of Labour and industry between the strategy group and the "practice making" research group ensured that the learning from the latter influenced the Strategy. Quality standards are very precise for sales into international markets. In the case of apples, the choice that a picker makes determines profit or loss for the grower, because poor quality fruit has to be paid for in transport and sorting while an export quality apple will produce good returns. The cumulative decisions of thousands of workers are therefore a critical part of the value creation for growers and exporters. And yet, all labour-intensive parts of the production process operated with the expectation of very high worker turnover. There had been little training and no career structure attached to seasonal work. Losses attributed to poor labour quality as well as too few workers were high.

Of all the change programmes developed in the strategy, the most important was the concept of a return-worker temporary labour scheme. Without the promise of a sustainable and reliable labour supply, the employers in the industry had no incentive or reason to believe that they could move from the low-wage, low-productivity business model to one of investment, productivity and higher wages. Developing RSE was, therefore, critical to all the other change processes being developed under the Strategy. It also had to be the first to receive significant investment in order to arrest the huge losses that industry were suffering and provide the basis on which to plan and develop. 7 This was identified in the "practice making" research and in the Strategy as the fulcrum around which change could occur.

At the time that the Strategy was beginning to be implemented, the World Bank was very active in advocating temporary low-skilled labour in the Pacific for development reasons. They worked with the Pacific Cooperation Foundation in New Zealand, which produced a conference on the issue. Policy development by the New Zealand Immigration Service (a part of the Department of Labour) was already being undertaken. using the ideas from the Strategy and the "practice making" research, and information gathered at the conference and elsewhere. These influences drew together to create a positive environment for development of RSE (Carroll et al, 2008).

The development of a return worker policy was announced by the Prime Minister at the Pacific Forum in late October 2006, having been agreed by Cabinet not long before that (the concentration on the Pacific may have been the key decision that enabled the scheme to proceed - see Eppel et al, 2008). The launch date for RSE was to be March 2007. This was a very ambitious target. The focus on the Pacific meant that the Department of Labour had to build a new set to arrangements with Pacific governments, five were initially targeted: Kiribati, Tuvalu, Samoa, Tonga and Vanuatu - the 'kick start' states. The development of Memoranda of Interagency Understandings with Pacific 
Island Agencies formed an expanded process to bring together the objectives of Pacific states, and the potential workforce, and employers in New Zealand; mediated through the government agencies.

Following the Scheme's launch late in April 2007, there was considerable anxiety in industry about the costs of the Scheme and how these might prevent smaller employers, in particular, from making use of it. After some months and much discussion, a transition process was established. This was able to be done because of the relationships established over the preceding years, and the commonly held objectives of the industry, government, Pacific and Council of Trade Unions.

\section{RSE and the Strategy are evolving as a practice, not a policy}

The RSE Scheme is becoming a complex system in its own right, and the interaction of it with the preceding labour market dynamics is an exercise in adaptive system change, guided by participants but not able to be controlled by them. The success of the RSE Scheme's development will be determined by the accuracy of the system's analysis undertaken previously, and participant's ability to adjust in the face of changes.

The success of RSE has consequences for the industry as a whole, for the first time in six years there have not been significant labour shortages in any of the major horticulture or viticulture regions. Smaller employers benefit through accessing casuals not needed by larger RSE employers. Investments have been able to be made, for instance $\mathrm{Mr}$ Apple Ltd undertaking bud-thinning of fruit, which is labour intensive but yields much improved fruit quality, as well as the planting of new varieties and purchasing labour-saving technologies.

As important as the ideas are on which the RSE Scheme and other interventions are based, increasingly what is more important is the practice of participants. The implementation of the RSE Scheme is requiring all participants to learn new behaviours in order to make the ideas embedded in the Strategy to work. This is so for all participants. Evolution of new practice is rapid but experimental; an extensive network of industry. Pacific, government and union participants is actively engaged in sharing what works and what does not. The work of establishing these networks is conscious but not entirely planned. All parts of the system are involved and have a voice in the development of the Strategy and RSE, though not all participants have been satisfied with the process or outcomes. One recent example of this continuing evolution is the Hawkes Bay labour governance group (an industry and agency group that manages RSE allocations and wider labour issues) agreeing with the New Zealand Council of Trade Unions to enter into a Memorandum of Understanding concerning induction and pastoral care of RSE workers. This group is also building relationships with local Iwi and Hapu to assist with pastoral care, and as a bridge to longer term relationships with Maori youth, as potential 'key kiwis' for the industry. The group itself is a evolutionary development from the Strategy and RSE.

For reasons of space the important roles played by Ministers and the Inland Revenue Department have not be canvassed, but they have made considerable contribution. A number of Ministers have followed RSE and the Strategy development closely and made important interventions; Cabinet was often engaged with RSE. The interventions of IRD in pursuing tax fraud have been vigorous and had an impact, as has the introduction of a withholding tax for contracting. This compliance work, combined with the Department of Labour's workplace and border security compliance operations, have made some dents in the illegal activity.

\section{Because of competition from lower cost countries, added value from RSE is essential to its sustainability}

Creating additional value flowing from the RSE workforce is essential for the sustainability of the scheme. The policy obliges employers pay costs greater than for a New Zealand worker, for example paying half the airfare of the workers from off-shore. RSE workers must also earn at least a specifiable sum over the time of their employment, be paid at 'market rates' and be provided with accommodation and pastoral care. These incentives were designed to protect workers, but also to improve cooperation between employers so that they would share risks and provide extended periods of work. It was intended that the RSE Scheme would develop a 'core' workforce that could be planned for and around, and these incentives encourage that. Whether the settings are encouraging the right behaviour will be an issue for ongoing consideration; unintended outcomes in a complex adaptive system are inevitable.

The collaborative behaviour from employers was also designed to encourage more use of New Zealanders by employers. The long-term unemployed, sole parents and other groups disadvantaged in the labour market are being assisted into work in the industry with the help of the Ministry of Social Development. Employers are now forming relationships with the prison services to develop 'work to release' training programmes for prisoners preparing to re-enter society. Soon refugees will also be recruited into the industry, with assistance from the Ministry of Social Development and Department of Labour. One outcome in the past year, through these relationships and RSE, has been that in Northland the proportion of New Zealanders grew from $65 \%$ of the workforce to $85 \%$. Backpackers were used proportionately less as a result.

Sustainability of labour supply is the purpose of the Strategy, and the RSE Scheme provides the most important vehicle for achieving that. An investment opportunity for employers has been established through returning migration. Employers now have a reason to consider skill development and investment in other infrastructure needed to ensure labour can be actively managed. In the past employers that wanted to take that 
approach found workers were quickly 'poached' by others who offered higher wages and did not want to make the investment in their workforce or business. Few employers were prepared to take that risk given the labour market conditions they faced. RSE helps provide both a level playing field where all employers are likely to make that investment, and where that will be rewarded.

The title of RSE - Recognised Seasonal Employer - was fully intended to provide the basis for a brand for New Zealand employers, one they could use both on-shore when co-operating or contracting with each other, and off-shore with retail buyers and the Pacific states. The purpose is to provide validation of a high standard of employment practice. ${ }^{8}$ This can be the core of 'social sustainability'. As such, it is anticipated some employers will seek to become recognised even if they are not intending to bring in off-shore labour. Industry representatives have speculated that being recognised might become part of a business's assets, just as having access to water is an asset. It is through this development of both a sustainable labour supply, and adding value to that supply to offset the costs, the Scheme will be sustainable in the longer-term.

An important part of this developmental process is exploring opportunities for joint venture developments in the Pacific. With the development of a skilled labour pool returning home for much of the year, and remitting large sums, for the Pacific, there are potentially many routes for increasing both for the benefit of Pacific economies and New Zealand horticulture and viticulture. There are good reasons to anticipate this development: complimentary rather than competing crops that are possible; trained staff with trusting relationships; the establishment of "village-to-village" relationships; increased New Zealand familiarity with the Pacific; the remittances going to communities because of the "villageto-village' relationships. In particular, there is considerable scope for organics, as there has not been the capital to industrialise agricultural production in the islands. Participants in the RSE Scheme are actively pursuing the potential development of this type of trade. Earlier this year a group of RSE employers visited Vanuatu, sponsored by the Pacific Islands Trade and Investment Commission, to consider business opportunities there; there are four possible developments occurring as a result. The Tongan government is discussing with one RSE employer the potential for establishing a worker cooperative to provide off-season and employment for those in the community that do not participate directly in RSE.

Undertaking this type of joint-venture would provide incentives for workers to return home (not abscond), enhance the stability of the supply of labour for employers in New Zealand, and expand the product range and potential markets for those engaged. On the Pacific side it would contribute to human capability development and economic development through skill and capital acquisition. Partnership would reduce risks on both sides, speed development and increase the value of RSE considerably.
The World Bank and others have drawn attention to the Pacific being the highest cost corridor for remittances in the world, with fees of between 15-25 percent. Research has established these costs have led to a lot of informal channels being used - with resulting losses of potential bank business. ${ }^{9}$ RSE provides another break point in the system, with a considerable amount of money being banked (as required under RSE policy) that will also be remitted. A combination of moral suasion, customer demand from workers and employers, and the prospect of new markets that could exploit high volume electronic transaction processes at low cost, is causing banks to rethink on the model they are are using. Westpac has just announced that they will introduce a debit card system that will reduce fees to less than 7 percent of the transaction. Other reductions and services are likely. In part this has been made possible because of changes to New Zealand's banking regulations - the Reserve Bank, NZ Aid, Pacific Island Affair led a project to bring this about.

\section{Conclusion}

There are many opportunities for sending and receiving countries to benefit from low-skilled migration. The sending countries will receive remittances, improve human capability and make connections that may be important for future trading relationships. The receiving countries can alleviate labour shortages, ensure an ongoing labour supply and build a skilled workforce.

The literature discusses the benefits and risks that have to be managed. For example, the politically sensitive nature of low-skilled migration or the risks of brain drain for sending countries. The literature does not, however, fully discuss a fundamental issue for the sustainability of schemes of temporary, low-skilled migration - the importance of the receiving labour markets being well understood, and the risk mitigated of them being 'trapped' in low cost and low productivity modes through migration. Ideally, schemes should be constructed that add value for all parties, and that continue to do so. How that is to be done is not necessarily straightforward or easy, given that the receiving markets may have considerable levels of dysfunction. The sensitive nature of low-skilled temporary migration means that the usual economic and regulatory incentives that can be deployed will not be sufficient to ensure timely adjustment and a sustainable scheme.

Being able to identify the 'value-add' moments and the combination of interventions that will achieve them, it is suggested, requires a different approach to policy making. "Practice making" is argued to be a better approach; that is one which involves a range of stakeholders in the construction of shared objects and identified behaviours that will be followed by agreement, then working back to the policy needed to support them. This is an approach that is able to guide the development of solutions for "wicked problems" and manage complex adaptive systems, which is what labour markets, and temporary migration schemes into which they send workers, are likely to be. "Practice making" relies on detailed systems 
analysis, experimentalism, and the establishment and active management of new social networks to create new behaviour. RSE and the Strategy are examples of this approach. Their success, to-date, would have been impossible or much less likely without the implicit and explicit use of this approach to the work.

Further Research

The Strategy is currently being reviewed. The review documents will be available at some later point. The likely direction of the Strategy will be to focus more on skill and productivity outcomes, devolve more work and decision making to regional groups, and take a more holistic approach to labour, not just seasonal labour, needs. These directions are, however, still under discussion at time of writing. Inevitably more work will also go into the "New Zealanders First" aspect of the policy. This is welcomed by industry.

The Department is in the relatively early stages of an engagement with the Meat Processing Industry, where the "practice making" approach is being tried. In the New Year it will be clear whether the participants will wish to pursue this approach further. The Department also has other engagements where "practice making" may be used in the future. The Oil and Gas Industry's "Producing the Talent: New Zealand Oil and Gas Industry Skills Action Plan", released October 2008, owed some of its early development to "practice making" approaches.

\section{Notes}

1. Go to: http://www.jobscentral.co.nz/ for Seasonal Solutions Central Otago.

2. Personal conversation with the $\mathrm{CEO}$ of SSCO.

3. The Scheme requires that all suitable New Zealanders are employed first. then workers from Pacific Forum countries (with the exception of Fiji pending its return to a democratic government following a military coup), then other countrys' workers. If an employer already has an established relationship with workers from another country outside of the Pacific Forum, they may continue to recruit seasonal staff from that country. If there are no suitable New Zealand or Pacific Forum workers, employers can recruit from any other country.

4. A joke that always gets a wry smile from industry is: "What's the difference between a TESCO's buyer and a terrorist? ... You can negotiate with a terrorist."

5. "Wicked problems" are ones that: "have incomplete, contradictory, and changing requirements; and solutions to them are often difficult to recognize as such because of complex interdependencies."

http://en.wikipedia.org/wiki/Wicked problem, Google provides lots of 'hits', one being the Australian Public Service Commission: "Tackling Wicked Problems: A Public Policy Perspective"
(2007).

http://www.apsc.gov.au/publications07/wickedpro blems.htm

6. For discussion of these issues in the EU, see as an example:

http://europa.eu/rapid/pressReleasesAction.do?refe rence $=\mathrm{MEMO} / 07 / 188$

7. As an example of those losses, Zespri lost $\$ 100 \mathrm{~m}$ in export earnings in 2006, and they estimated that $\$ 20 \mathrm{~m}$ of that was because of lack of labour and poor quality labour leading to damaged fruit and expensive repacking of export fruit.

8. Pacific State's permission for this branding to be used in this way is integral to the development process.

9. John Gibson, a contributor in this session, has been one of the driving forces in this work.

\section{References}

News stories relating to Morecombe Bay cockling are available at:

http://news.bbc.co.uk/2/hi/uk_news/4238209.stm and

http://news.scotsman.com/topics.cfm?tid=1083\&i $\mathrm{d}=908362004$

Carroll, P., Blewden, M. and Witten, K. (2008) Building Research Capability in the Social Sciences (BRCSS): The Social Sciences and Policy Research Use, Centre for Social and Health Outcomes Research and Evaluation, Massey University, August 2008, available at: http://shore.ac.nz/projects/BRCSS\%20Research\% 20 to $\% 20$ Policy $\% 20$ Final $\% 20$ Report $\% 20$.pdf

Chapman, J. System Failure: Why Governments Must Learn to Think Differently (2nd ed.), Demos, London, available at: http://www.demos.co.uk/publications/systemfailur e2

Dayton-Johnson, J., et al. (2007) Gaining from Migration: Towards a New Mobility System, 2007, OECD Development Centre; and.

Dayton-Johnson, J. and anor, (2006) Migration, Aid and Trade: Policy Coherence for Development OECD Development Centre Policy Brief No.28, 2006; and a number of other papers on migration, trade and aid, are available at: http://www.oecd.org/document/0/0,3343, en 2649 _33935_39207488_1_1_1 1,00.html

Eppel, E., Gill, D., Lipps, M. and Ryan, B. (2008) Connected Services for Kiwis: a Discussion Document for Managers and Frontline Staff, On Better Joining Up the Horizontal and the Vertical, Institute of Policy Studies, Victoria University, 
2008. available

at: http://ips.ac.nz/events/completedactivities/joiningup/Connected $\% 20$ Services $\% 20$ ve r\%2010.pdf

Hill, R. et al. (2007) "Workplace learning in the New Zealand apple industry network: A new co-design method for government 'practice making'", Journal of Workplace Learning, 2007, Volume:19 Issue: 6 Page: $359-376$, available at: http://www.emeraldinsight.com/Insight/viewConte ntItem.do:jsessionid=CD44B18E75BD9D2F3897 FA75B1686F4B?content Type $=$ Article\&contentId $=1621051$

Horticulture NZ et al (2005) The Medium-long Term Horticulture/Viticulture Seasonal Labour Strategy, 2005, available at:

http://www.hortnz.co.nz/activityareas/seasonalwor k.html

OECD Development Centre, (2007) Policy Coherence for Development: Migration and Developing Countries, 2007

PEPANZ and Department of Labour, (2008) Producing the Talent: New Zealand Oil and Gas Industry Skills Action Plan, October 2008, available at: http://www.pepanz.org.nz/documents/DIR\%20108 17\%20Taranaki\%20Oil\%20and\%20Gas\%20Skills $\% 20$ Action\%20Plan.pdf

Sparrow, M. (2000) The Regulatory Craft - Controlling Risks, Solving Problems, and Managing Compliance, Brookings Institution Press, 2000

Wellings, R. and Blundell, J. (2004) The Morecambe Bay Cockle Pickers: Market Failure or Government Disaster? Economic Affairs, Vol. 24, No. 3, pp. 69-71, September 2004, available at SSRN: http://ssin.com/abstract $=591421$

Whatman, R., et al, (2005) From Policy to Practice: The Pure Business Project. Proceedings of the 11th ANZSYS / Managing the Complex V ConferenceSystems Thinking and Complexity Science: Insights for Action, Christchurch, New Zealand, 57 December (2005) available from ISCE Publishing, available

at: http://isce.edu/ISCE_Group_Site/webcontent/ISCE\%20Publishing/ISCE_Publication_S eries.html

World Bank, At Home and Away - Expanding Job Opportunities for Pacific Islanders Through Labour Mobility, 2006, available at: http://web.worldbank.org/WBSITE/EXTERNAL/ COUNTRIES/EASTASIAPACIFICEXT/PACIFI CISLANDSEXTN/0,,contentMDK:21020027 pag ePK:141137 piPK:141127 theSitePK:441883,00. html

\section{Authors}

Richard Whatman Work Directions Group Department of Labour PO Box 3705

Wellington

National Seasonal Co-ordinator Horticulture New Zealand Richard.Whatman@dol.govt.nz

\section{Jerf Van Beek}

National Seasonal Co-ordinator Horticulture New Zealand PO Box 10232

The Terrace

Wellington 6143 